\title{
VIOLENCE AND UNCONSCIOUS STATE OF EPILEPTICS, IN THEIR RELATIONS TO MEDICAL JURISPRUDENCE
}

BY M. G. ECHEVERRIA, M. D.

Are the acts of violence committed by epileptics always the direct offspring of a paroxysm, or merely effects of the intellectual derangement induced by the disease? The great breadth of this question has already been acknowledged by the prominence attached to its elucidation by those especially devoted to the study of epilepsy, and whose valuable inquiries have thus far disclosed, that many extraordinary misdeeds, ascribed to crime, are originated by epilepsy. Delasiauve states; that, "one half of the homicides perpetrated by lunatics arise from no other cause, and that the trouble attending epilepsy is a prolific source of catastrophes." Maudsley declares no less positively that, "there can be no question in the minds of those who have studied mental diseases that certain unaccountable criminals belong to the class of epileptics. Lastly, $\mathbf{J}$. B. Thomson, Resident-Surgeon to the General Prison for Scotland, at Perth, in a most valuable paper on the Hereditary Nature of Crime, concludes; that, "out of a prison population for ten years amounting to 6,273 , or 627 per annum, the percentage of criminal epileptics under my charge was 0.94 , or nearly one per cent. per annum, very different from the army and civil population of England, where the death-rate of epileptics is estimated at 0.009 par cent. only. There is, therefore, 
a great excess of epilepsy among criminals."* The pernicious influence of epilepsy must therefore be very potent, though scouted by Courts of Justice. The possibility of homicide or other criminal actions cropping out of perverted affections, or a well-marked intellectual impairment, which irresistibly compels the epileptic to obey his morbid impulses, and destroys the judgment, for a proper recognition of his feelings and actions, through exaggerated passions and instincts, are equally declared by law of no account. Furthermore, the paroxysms of unconsciousness, or abstraction, differing altogether from the ordinary fits, during which acts of violence frequently occur, have been scarcely described by any author on epilepsy.

The subject under consideration ought to be examined in the connection of the epileptic seizures with the above intellectual disorders. Such an investigation covers broad grounds, rich in interesting themes, which have already been thoroughly developed by Delasiauve, Boileau de Castelnau, Falret, Morel, Trousseau, Legrand du Saulle, and other no less eminent alienists. I will not, therefore, go over fields where they have left little to be gathered, but confine my investigation within the circle of those cases, still obscure and perplexing, of hidden nocturnal epilepsy; or of fits occurring not in an antecedent but in a subsequent relation to the criminal act of violence; as also to cases where the morbid impulses are developed altogether detached from and independent of any visible fit, spring. ing irresistibly into action out of the subtratum of an unhealthy mind, and really denoting a state of unconscious cerelration, derived from a masked or cerebral fit, in which state most of the crimes calling for a medico-legal investigation are perpetrated by epileptics.

It may not be uninteresting to classify in a brief and

*Journal of Mental Science, Jan. 18\%0. Vol. XV. p. 496. 
general way the different forms of epileptic attacks before referring to any of the mental phenomena that might attend them. Delasiauve distinguishes four kinds of epileptic fits, to wit: 1. Fits of absence, or intellectual eclipse lasting but a few seconds, with paleness of the face and stupefaction as its signs. 2. Vertigo, or more or less prolonged obliteration of feeling, with partial convulsions of the face, or sometimes of the upper regions of the body. 3. Intermediate attacks, characterized by general shocks, extending with variable uniformity over the body, or exclusively seated on one side, lasting one or more minutes, and the fall, when it takes place, resulting from a loss of equilibrium. 4. Grand attacks, when, suffering a much fiercer storm, the individual is overthrown as if struck by an irresistible shock. The difference established by Delasiauve between the vertigo and the intermediate attacks is purely speculative, since it implies a distinction which does not exist; for both varieties actually differ in degree of the convulsions, and approach so closely to each other, that to nobody is it given to fix where vertigo ends, and the intermediate attack begins, nor to recognize them by the consequences which are analogous in either case. Calmeil, who was the first to show the true epileptic nature of the fit of absence, looks upon it as an averted attack of vertigo; whereas Herpin asserts, that it is always possible to detect some slight partial convulsions in every case of absence, a fact which my experience fully corroborates. Herpin further contends, that intermediate attacks are never ushered in with complete unconsciousness, or with the initial cry. Delasiauve contradicts the statement, as I believe with good reason, because he has always detected absolute unconsciousness, though he has failed in several instances to observe the cry at the onset of the attack. I have 
thus cursorily alluded to the disagreement between these high authorities, to show the impracticability of Delasiauve's division, which really offers no clinical or medico-legal advantage over the simple classification of epileptic fits I adopt, into petit mal and grand mal, or falling sickness. No species exist without varieties that mix and blend with each other, or with those from similar approximate classes. It is besides clear, that it does not follow as a matter of course that the distinctive conditions applicable to the rarieties of one species are always so to the next; wherefore intermediate varieties are not classified separately, but among the species they resemble most in their principal traits or original characters. The petit mal, consequently, includes all fits of absence and vertigo, or those paroxysms where unconsciousness is the predominant feature, convulsions being almost absent, or an unimportant element. To the grand ma? belong those attacks displaying unconsciousness and convulsions, with stertor and coma, in a greater or less degree. If any line of demarcation were to be made between the petit mal and grand mal, I should consider the statement of Marshall Hall perhaps nearer than any other to the truth, namely, that the presence of trachelismus converts the petit mal into grand mal.

Epilepsy may yet display itself under the larvated or masked form, described by Morel. One of his late internes at the Asylum of Saint Yon, Dr. P. Leblois, in his inaugural thesis "Sur les rapports de l' epilepsie avec la Manie périodique, Paris, 1862," gives very happily the name of cerebral epilepsy to the mental derangement here in question, conversely to the so-called spinal epilepsy of Brown-Séquard and other authors, to which it bears no relation further than the name. Sudden, transient, or prolonged outbursts of maniacal 
excitement without any contemporaneous convulsions, are the main characteristics of cerebral epilepsy, supervening either as the forerunner or sequel of, or alternating periodically with either of the two other forms of epileptic paroxysms.

Finally another important variety is the nocturnal epilepsy, that seizes the patient in the night during his ordinary sleep. Such attacks, though of long standing, may often remain unsuspected by the patient, and not infrequently they also escape the notice of the physician. They ordinarily occur without inducing great agitation or muscular contraction, revealing their presence in the majority of instances, chiefly by the stertorous breathing, or the initial piercing cry sometimes uttered by the patient, who continues profoundly asleep after the paroxysm and wholly unconscious of his condition. The effects of these attacks are manifest in the morning, when the patient wakes up with a headache, confusion of ideas, dull eyes, pupils enlarged but not always equally dilated, and in some cases, with several petechiæ, or minute ecchymoses on the eye, forehead, face, or neck. In other instances the eyes are suffused and the face bloated, with the characteristic expression peculiar to epilepsy. Furthermore, not only are lacerations evident in one of the edges of the tongue, when this has been bitten during the fit, but stains of blood and saliva on the pillow or hed clothes will betray the occurrence of the attack. Other injuries may result from any unnatural position in which the limbs may be thrown during the fit, a fracture of the bones, or dislocation of the joints, being in this wise produced; whilst death may also supervene from suffocation of the patient by placing his head, during the fit, in a position that will impede respiration, as happened to a female epileptic 
at the Hospital, who was discovered in the morning dead, lying on her face with her head buried through the opening of the tick in the straw of the mattress. The involuntary passage of urine or excrements, during the paroxysms, without the patient being conscious of it, has also a very great significance in establishing the presence of nocturnal epilepsy.

No difficulty attends the recognition of epilepsy when a paroxysm of grand mal has induced that of mania during which the criminal act of violence has been perpetrated. But, when the culprit is subject to nocturnal attacks, or simple petit mal, when the traces to the unpracticed eye are faint, to demonstrate the disturbing cause and bring the facts of the case to satisfactory computation, is a problem that can only be solved by a thorough acquaintance with the fundamental as well as with those apparently secondary conditions pathognomonic of epilepsy. Personal experience has shown me, that the larvated and nocturnal attacks, and the petit mal, disturb the nervous centers alike in structure and in function more rapidly than the fits of grand mal. Trousseau asserted, with great correctness, that all nocturnal accidents should suggest epilepsy. How easily the silent nocturnal paroxysms are overlooked, is as much illustrated by ordinary as by criminal cases. Their diagnosis, therefore, demands the nicest discrimination, for no kind of epilepsy is more liable than this to originate mental derangement, with impulsive criminal aets.

The following are examples of homicidal assaults and violence, after attacks of nocturnal epilepsy, which would have greatly perplexed, as to their true character, those unacquainted with the epileptic condition from which they sprung. It is needless to remark how much these acts, taken by themselves, would have enbarrassed the question of the legal responsibility of 
these epileptics, one of whom was almost providentially saved from the gallows.

CASE I. A printer, moderately temperate, enjoyed good health till July, 18b4, when he received a blow on the head from a cog-wheel of a printing press. The blow fell upon the right parietal bone involving the suture, and to a slight extent, the left parietal bone, also leaving a linear cicatrix of the scalp, without injuring in any noticeable manner, the bone underneath. The accident rendered him insensible for about ten min. utes, but did not prevent his resuming his work. For about four months afterwards he suffered from slight but frequent headache, which was aggravated by drink. His first fit occurred while at work, a few months after the injury. The night previous to the fit he had indulged more than usual in drinking. Three months later he had a second nocturnal fit, and thereafter the attacks occurred at intervals of about two months. 'They gradually became more frequent and he had one every two weeks until about nine months before his admission into the Hospital, (October, 1869,) when the attacks occurred less frequently, but always with their previous nocturnal character. The patient was of a quick, irritable temper. For two nights before the 30 th of March, 1870, he was discovered by the watch. man going slyly to tumble a helpless paralytic out of bed "for the sake of fun." On the 30th of March upon being quietly addressed by a harmless companion, the patient became furious, violently assaulted, struck sev. eral times at him, and severely injured his left eye. He remained entirely quiet after this unprovoked act of violence, and continued his work of setting the table for the other patients' breakfast. He offered no excuse for the assault he made on his companion, merely saying "that he could not help it, being provoked by his remarks." 
CASE II. A sailor, aged 38, became epileptic after an injury to the skull by falling from the top of a mast. He was also troubled with polyuria. The fits displayed usually a nocturnal character, returning my times in succession in one night, followed during the day by a stupid condition, which changed after some hours into a talkative and incoherent state. One morning, after breakfast, on being casually spoken to by another patient, he rushed at him furiously, and seizing a knife near by would have stabbed him, but for the immediate interference of the attendants. It was noticed that he had had several fits the night before. This man, of a peaceful though moody disposition, was, on several other occasions, subject to sudden outbursts of fury, when be would attack any person near him. He felt very much distressed by these fits of madness, but obstinately concealed his dreadful feelings and hallucinations of hearing, and on this account avoided the society of his companions. He had, also, been committed several times to the workhouse for disorderly conduct.

CaSE III. A gentleman, aged 34 , has been subject from the age of twelve to nocturnal fits, always ushered in by an acute cry, as though he were harassed by a fearful nightmare. He has besides petit mal, and frequently becomes very melancholic, but the rest of the time exhibits a gentle inoffensive disposition. His maternal grandfather was insane, as were probably other members of his family. They are, however, very reluctant to afford any information on this point, and maintain the deepest secrecy regarding the suicide of a maternal uncle of the patient. One morning, three years ago, upon waking, after having experienced two paroxysms during the night, he went into his brother's room, and began to pace up and down very fast. Without speaking a word, he seized his brother's razor 
and cut across his own throat, inflicting a serious wound. Had not his brother secured him the attempt at suicide would have been successful. On another more recent occasion, this epileptic, while at breakfast with his sister, when she asked him if he wished for some coffee, suddenly rushed at her. She saved herself by quickly calling for assistance. When the mother and brother entered the dining-room immediately after, they found him leaning on the back of an arm chair, very pale, grasping a knife in his right hand, but unconscious, in one of his paroxysms of petit mal. He had had a fit during the night.

Case IV. I was consulted last December, by a gentleman from Metuchen, New Jersey, about one of his sons, thirteen years old. His maternal grandmother and uncle were, the one insane, the other epileptic. This boy had gradually become very ungovernable, being suddenly seized with fits of anger, in one of which he attacked with a rule another boy, and badly wounded him in the head. Strict discipline and correction have proved of no avail with hin, his dangerous proclivities having forced the schools to refuse him admission. He displays a great ingenuity for drawing, of which he is very fond, but has acquired a very rudimentary knowledge of reading and writing. His singular disposition to destructive acts, or mischievous cruelty, changes with a remarkable rapidity into gentleness and quietness. He has often threatened to kill his parents or brothers, and attempted last summer to set fire to his father's house. The father adds, that he has the nightmare habitually, and is troubled with nocturnal incontinence of urine, particularly at the time of his ungovernable, mad turns. The boy exhibits no marks of lacerations of the tongue, but says that he feels dizzy in the day time; "that things wheel around him." His head looks 
regular and well developed; the pupils are very large, and the extremities cold and purple. His intellect is of a low order; he is silly in bis remarks, and given to mischief as soon as left alone. Another prominent trait of his character is, a proclivity to steal everything from his brothers or parents, as soon as the least opportunity offers itself.

I diagnosticated nocturnal epilepsy, which was verified when the parents watched the boy more attentively. What was supposed to be a nightmare was a real nocturnal epileptic paroxysm. I advised, on account of the unpromising nature of his disease, that the boy should be placed in some institution for the insane, for as he would be likely to commit homicide or arson when in the above detailed condition of epileptic insanity, I deemed it very unsafe to allow him complete freedom.

Case V. Years ago, a laborer in this city, named Macdonald, in the middle of the night killed his brother, who occupied the same bed with him. $\mathrm{He}$ grasped him by the neck until he strangled him, and as he could not account for his murder, it was consequently looked upon as a most wretched and flagrant crime. Macdonald remained, while in prison, utterly indifferent to his position, and would give no satisfactory history of his antecedents. The very night before the day fixed for his trial, he was at a late hour taken with an epileptic fit, during which, he violently seized by the neck another prisoner confined in his cell, and would have strangled him to death, had not the keeper come promptly to his assistance. Macdonald was in great fury at the time, beyond all control; the next morning he appeared as calm as usual, and had no knowledge whatever of the homicidal struggle in which he had bein engaged a few hours before. The trial, of course, 
had to be postponed after this event, and the late Dr. M. H. Ranney, of the City Lunatic Asylum, was directed by the Court to examine into the mental condition of Macdonald. As soon as the Doctor saw him, he recognized an epileptic he had discharged from the Asylum some months before, and who had been subject to nocturnal fits attended with homicidal mania. This interesting information has been furnished me- by the lawyer who was appointed by the Court to defend Macdonald, whose fate would have probably been different without the occurrence of that nocturnal attack, inasmuch as his execution was loudly demanded by the press and public clamor.

On the subject of vertigo, or nocturnal epilepsy, and the judicial errors to which these doubtful cases lead, Dumesnil writes:

"I have treated a great many epileptics who exhibited their attacks at long intervals, experiencing thereafter an irresistible impulse to strike other persons, to steal, to commit arson, etc., etc., but who returned afterward to their usual state, without displaying any indication whatever, beyond their antecedents, to account for their evil inclinations. How easy it is to err in such instances if we solely judge from present actions without resting on any other safer data?"

"A young epileptic, who had committed several thefts was recently transferred from the prison of Bicêtre to Quatre-Mares : he managed to escape thirty-six hours after admission, when he seemed hardly recovered from a fit, and was arrested the very next day near Louviers for burglary. Nothing, in the answers of this man betrayed the disease in question. However, the imperial attorney, without discontinuing proceedings, kept him under close guard, and when the information was received from the Prefecture, he immediately became convinced of the frequency of the fits, their attending intellectual derangement, and the complete mental recovery intervening between them, wherefore the return of the patient to the asylum was at once ordered."

"There are other cases still more perplexing, namely, those in which the convulsive accident is only reduced to a slight vertigo, 
that may for a long time pass unnoticed, although nevertheless attended by the most strange and dangerous morbid incitations. I possess some very curious observations of this kind, on which point there is a lack of scientific documents."

"A soldier subject to more or less frequent outbursts of passion, was brought before a court martial on a charge of having gravely insulted his superior officer. A medical investigation was instituted, and thereupon the arraigned soldier was transferred to an insane hospital, where it was ascertained that he was subject to mild attacks of periodical mania. Long afterwards I had occasion to satisfy myself that each one of these attacks was preceded during the night by a light nervous fit. This condition had passed ignored by-the patient himself, by those who for several years had slept every night close to him, and by those who attended him."

"At the present time three of my patients at Quatre-Mares have only been considered epileptics for eighteen months, after having spent several years at Saint Yon and the new asylum, without this dreadful complication having been suspected. These insane patients are the most dangerous, their fury breaks out suddenly and is directed alnost always against some person, most frequently terminating in the quickest manner, and recurring at such distant intervals that one might think it a complete recovery after a simple fit of mania."

"I would take pains to affirm that there is now no patient at the Institution under my direction, whose insanity is not intimately associated with slight nocturnal attacks, which up to the present have escaped our attention, and may become recognized at any moment after a stronger attack, or a fit of vertigo in the day time, as it happened with the patients just alluded to."

"A man arraigned for larceny, and recently admitted into Quatre-Mares, whose physiognomy had struck me, and whose delirium exhibited very similar characteristics, was discovered a few days ago, as having epileptic fits during his sleep. At present this man evinces no signs of insanity, and does not recollect the larceny he committed, or the circumstances connected with it."*

The high authority of Dumesnil in psychological medicine, and the great medico-legal value of his ob. servations, are chiefly my reasons for coupling them with the preceding in a group. I have thought neces-

* Les aliénés et les enquétes médico-légales.-Journal de Medecine. Tome I.. 1861 ; pp. 255, 256. 
sary to supply a deficiency of well-authenticated and precise facts to bring truth to light concerning the criminal responsibility of epileptics, who, through judi. cial prejudices, or error on these ohscure points, have been held accountable for their actions, and too often, condemned without mercy.

I will make besides, brief reference to another case cited by Morel: A young man condemned to five years' imprisonment by a Court of Assizes, for having, without provocation, inflicted a nearly fatal blow on one of his hest friends, was subject to epileptic fits during his sleep. Morel had the opportunity of verifying the fact at the prison where this young man was incarcerated. This unfortunate sprung from a family among whose ancestors were epileptics, lunatics, and others who died of cerebral hemorrhage. He had no distinct recollection of the act for which he had been tried, nor did he show the least grief; and such an apparent insensibility, the result of his disease, helped in no small degree to condemn him. Morel further remarks, that, on repeated occasions, this young man had struck his friends, without provocation, and that he exhibited dullness and hypochondria.*

The involuntary passage of urine has already been pointed out as one of the signs of nocturnal epilepsy, and I have noticed one instance in which it led me to discover the unrecognized attacks. The importance that may attach to this symptom, and the singular intellectual perversions that may be induced by epilepsy, are vividly illustrated in a recent extraordinary criminal case, submitted to Legrand du Saulle for examination an!l report, and by him presented to the consideration of the Medico-Psychological Society of Paris, on the 29 th of January, 1872. The case is, indeed, excep-

* Traití des Maladies Mentale: Paris, 1860; p. 695. 
tional in every respect, and I give the leading points of its history, as worthy of attentive study.

CASE VI. A young man, belonging to a distin. guished family, was at the age of 18 , regarded as "a queer fellow," without memory, and occasionally liable to fits of unprovoked anger and violence. At 19, while in college he had, as he says, brain fever, which for two or three days rendered him so delirious that he had to be restrained. From this attack he recovered suddenly. He at this age unconsciously wet his bed during his sleep, five or six times in a year. $\mathrm{He}$ entered the Military School of Saint Cyr, studied well, and was of good deportment, though he always suffered from what he called "weakness of the bladder." After two years of study, he was appointed under-lieutenant in the African army. There he became difficult to please, quarrelsome, insolent, pettish, addicted to drinking absinthe, and at times uncontrollable. He was punished by his colonel, and having fought a duel, had on this account to abandon his regiment, and joined one of turcos, among whom he was no less disagreeably situated. He suffered at this period so much from nocturnal incontinence of urine that he had to pay for the consequent damage to his bed. During a long march through the province of Constantine, he fainted, was carried to the hospital, and there treated as affected with sunstroke. When recovered, he rejoined the turcos regiment, but caused so much trouble that he incurred a severe punishment from his general, after which he tendered his resignation, and without taking leave of anybody, returned home in June, 1870. $\mathrm{He}$, however, felt ashamed at his resignation, when the war broke out with Germany, and dreading to be branded as a coward, enlisted as a private, and fought in several engagements before Metz; was taken prisoner, vot. XXIX.-No. IV.-F 
but succeeded in making his escape from the church at Pont-ä-Mouson, where he had been confined with some other soldiers. He reached his home after severe hardships, and noticing that new armies were being recruited to meet the exigencies of the war, he wrote to Gam. betta that he had been promoted to the rank of lieuten. ant and decorated a Knight of the Legion of Honor while before Metz, and begged for a command becoming his rank. Gambetta sent him a lieutenant's commission and orders detaching him to the Loire. He had his left shoulder crashed by a ball, at the battle of Coulmiers, and, being picked up by an ambulance, was thereafter treated in different places, but did not fully recover from his wounds. His real position, in the meantime, became known to the military authorities, who had him arraigned before a court martial: 1, for desertion in presence of the enemy, when escaping from the church at Pont-âa-Mouson, without at once joining his regiment; 2 , for making the false pretense of having been promoted lieutenant before Metz; and 3, for claiming he had been decorated a Knight of the Legion of Honor.

On examining this young man at the military prison, Legrand du Saulle found him calm, gentle, intelligent, pale and of a sickly appearance; but otherwise sincere, confident and resigned, though earnestly protesting against the imputation of cowardice or insanity. The eminent French alienist declares, that he attaches such a weighty symptomatic value to the nocturnal incontinence of urine, that, under the circumstances, irrespective even of the psychical peculiarities displayed throughout the agitated and harassed life of the prisoner, he should affirm the existence of epilepsy, even if the supposed brain fever at the college, the attack of sunstroke in Constantine, and the other details already 
noticed, were not clustered around the case so as to leave no room for doubt on the subject. The difficulty, however, rests in another direction, and Legrand du Saulle thus alludes to it:

"Listen to what the Judge delegate of the court martial may say: I was ignorant that weakness of the bladder was a betraying sign of epilepsy, as I was equally ignorant that epilepsy could authorize a soldier improperly to wear the straps of lieutenant and the decoration of the Legion of Honor; but you state that such a thing is possible, and I believe your word. Yet, how does it happen that free from fits $\mathrm{C}$ - has persisted in wearing the straps and decorations, which ought constantly to have called to his mind an unconscious fallacy, a pathological error or crime on his part, and the excessive confidence of M. Gambetta in a French officer's word? I contend the physician will reply, that $\mathbf{C}$ labors under a neurosis, which transiently disturbs the intelligence. I believe that the letter to $M$. Gambetta might have been written in one of such deranged moments; but it is not in my province to appreciate the consequences of acts that occurred out. side of a state of delirium. The trial starts from an acquired irresponsibility, but fatally leads to a series of free and fraudulent acts. I acknowledge and deplore it. As a physician, I recognize and pass judgment on the starting point; but as a man, $I$ leave the judgment of the point of termination to the wisdom of the Court."

In this dramatic instance, epilepsy had existed un. heeded for almost fourteen years, the nocturnal incontinence of urine being the symptom which drew Legrand du Saulle's attention, and caused him to recognize the singular and mysterious nature of the criminal actions, spacified in the charges against the prisoner. To satisfy the Society that he had not overestimated the value of this symptom, Legrand du Saulle referred to other cases under his own observation, and reminded it of the important significance which Trousseau always gave to this phenomenon, that by itself had often enabled the great physician of the Hotel-Dieu to diagnosticate epilepsy. 
The foregoing cases, excepting Macdonald's, and the first quoted from Dumesnil, evince impulsive acts of violence, some of them of a homicidal nature, in epileptics who were apparently in a rational condition, though laboring under the unrecognized influence of $a$ previous nocturnal attack.

I can not pass over two circumstances therein mentioned, that I have met as prominent factors of epileptic insanity, namely: the hereditary predisposition to the disease, and injuries to the head. It is unnecessary to add, that when intemperance urites itself to either of these elements, it increases their potency and contributes most effectually to induce serere mania, or sudden fury. Two of the most violent epileptics I have seen, became such after fracture of the skull, and their fits were always excessively aggravated by drinking. The paroxysms of fury which one of them displayed for one or two days after the fits, were of a very extraordinary and dangerous character: both exhibited during this state alternations of calm and apparent rationality, though neither of them preserved any recollection of what they did or said at this time.

The combined influence of hereditary taint, traumatic injury to the head, and intemperance is strikingly illustrated in the following case.

Case VII. A carriage driver, whose grandfather was insane and whose mother was phthisical, became affected with epileptic vertigo and violent mania, from severe contusion to the head by being thrown from a carriage, against a lamp-post in the Central Park. No cicatrix existed at the site of injury over the posterosuperior angle of the left parietal bone, but the scalp and bone underneath were very sensitive to pressure. I trephined the skull and removed a portion of the bone, which was thick and hardened by inflammation. 
The maniacal excitement gradually disappeared thereafter, and he left the hospital, entirely recovered of his insanity, about four months after his admission. Hav. ing resumed his occupation and irregular habits of drinking, he died, five months later, with peri-encephalitis. This epileptic came very near killing one of his attendants, who was kindly dressing his wound a few days after the operation. The attack broke out suddenly, without the attendant speaking a word, just as he began to loosen the bandage around the head. After the impulsive fit of furor, the patient acknowledged that he was aware of doing wrong, but that it was more than he could do to help it, and that he had to give himself up to such an act of violence, "to quiet his nerves."

The readiness with which the most indifferent re. mark, or even the gentlest touch, may occasionally become an inciting cause of epileptic fury, has not escaped Delasiauve's attention, who prominently sets forth this apparently trifling circumstance that may nevertheless prove of so much legal moment. One of Delasiauve's patients rushed fiercely, and brutally struck at one of his companions, who had done nothing but ask for a place on the bench where he was sitting. Another burst into extreme fury upon being asked for the light of his pipe. I shall have occasion to refer to other instances, besides these I have already cited, of attacks of overwhelming fury, acknowledg. ing such motiveless incitations as their immediate cause, and could swell the list with several more exam. ples under my own observation.

The best safeguard, and one eminently worthy both of medical and legal attention, for a correct appreciation of the epileptic seizures, are the phenomena that immediately precede or follow them. It is a peculiarity of 
the epileptic paroxysm, that its premonitory symptoms, or rather its incubation, are ordinarily hidden and im. perceptible, not offering the least warning to the patient, and unrecognized even by careful watchers. In many instances, however, an aura, distinctly perceived, admonishes the patient for a few seconds or a longer time, of the approaching fit. Physiological experiments demonstrate the truth of the principle proclaimed by Marshall Hall, that epileptic paroxysms, like all reflex actions, must always be due to peripheral incitations. With an unequaled skill and sagacity, Brown Séquard has shown the existence of the unfelt aura, and the fact that irritation of certain peripheral nerves arrests, or prevents the attacks in artificial epilepsy. A further step has been achieved, in the experiments of Herzen and Lewison, evincing, that so long as irritation of the peripheral nerves lasts, no reflex excitability of the spinal cord can be brought into action. I shall not expatiate on these fundamental principles, which I briefly point out, as giving us the key to explain the sudden generation of violent impulses in an apparently quiet patient, upon the least moral or physical excitation, as well as the other singular phenomena of epileptic insanity. And, whether the aura acknowledges a peripheral origin, as physiological and pathological researches indicate, or whether it merely represents a mental accident, a delusional sensation, as believed by some authors, no point rests better settled in my mind than, that the aura, either felt or unfelt, is the harbin. ger of the attack, susceptible, as established by Trousseau, and as I have repeatedly seen, of entirely constituting it in vertiginous epilepsy, or in the sudden outbursts of fury supplanting the epileptic paroxysm.

The epileptic aura varies in nature and may involve the intellectual, sensorial or motorial faculties, or ex- 
clusively the vascular and secreting systems. Without stopping to delineate each of these varieties, with which we are so familiar, I will give place here only to the characteristics of the mental aura, scarcely described by any author. Falret writes:

"Just as different bodily derangements may precede the epilepsy by a few minutes or a few hours, for example several kinds of indispositions, headache, vomiting, pains of various sorts, or else the sensory or muscular symptoms to which the generic term of epileptic aura has been applied; so also the convulsive attacks of epilepsy may be preceded either immediately or at a greater or less distance, by different disorders of mind or temper. Thus, it happens, that certain epileptics become sad, pevish, irritable, quarrelsome, often for several hours before their fits. Others again, complain of slowness of conception, failure of memory, obtuseness of ideas, or a kind of hebetude or physical and moral prostration, which to those used to their society, or to themselves, are sure presages of an approaching fit. Others, lastly, display for several hours before the epileptic attack an unusual gaiety, an exaggerated sense of physical and moral well being, an unbounded confidence in their strength, and sometimes even a state of restlessness and loquacity which may be pushed on to maniacal excitement, or to violent outbursts of passion. Apart from these precursory symptoms, which may come on at a variable time previous to an epileptic seizure, there are other more immediate intellectual prodromata, a sort of intellectual aura, which only precedes the convulsive paroxysm by a few minutes and constitutes in a certain measure the first symptom thereof. We see, for example, some epileptics in whom the same idea, the same recollection, or the same hallucination springs up spontaneously at the moment of the invasion of each fit and infallibly precedes its appearance. The patient sees flames, fiery circles, red or purple objects, a ghost or a phantom, he hears the sound of bells, or a determined voice uttering always the same word, or lastly, he sometimes perceives the smell of a particular substance. These ideas and recollections, or these false sensations which are excessively variable as to individuals, ordinarily reproduce themselves with singular uniformity in the same individual at each new attack. It is further a curious fact, that very often this recollection, this idea, or this image, is the reproduction of an idea or a sensation which provoked the first fit in the 
patient. Many, in fact, who have become epileptic after strong mental emotion, or intense terror, behold again in spirit, or before their eyes, on each succeeding seizure the painful or the dreadful scene which first produced their complaint."*

I have availed myself of Falret's description, because it would be impossible to render a more precise and vigorous account of the intellectual aura than the one he has traced with such masterly strokes. The psy. chical phenomena peculiar to it, although not of constant occurrence, deserve the most attentive consideration, since their sudden supervention may render epilep. tics, not otherwise insane, extremely dangerous and liable to commit suicide, or murderous acts of violence for which they could not be held responsible, as evinced by the following example:

CASE VIII. A gentleman, subject to fits of grand mal every five or six weeks, manifests, for a day or two before, the most extraordinary ill-temper and sensitiveness, with a sad expression of countenance, and assaults or insults the by-standers without provocation. These propensities and periods of unnatural excitement are displayed before, but never after the paroxysm, and as this breaks out, he always sees, with the left eye, a hideous black and red human figure, which slowly mag. nifies as it approaches him. His head perspires profusely after the attacks, and no perceptible difference has been detected with the ophthalmoscope between the right and left optic nerves. This patient, during one of these premonitory stages, assaulted his attendant with a chair, and gave him a blow on the head, which left him senseless, because the attendant asked him how he was feeling. Then be ran to his sister in a frantic condition told her he had killed the attendant, and dropped in a fit. This epileptic is perfectly rational at other times, when he can render a circumstantial account of his dis- 
tressing feelings. During the temporary disorder of action preceding the fits, his eyes and cheeks become flushed, and he has to be kept in seclusion.

Falret, Trousseau, Delasiauve, Boileau de Castelnau, and others, have reported curious instances of intellectual aura, too well-known to need repeating.

Let me, however, briefly recall the singular case I have before detailed, of a demented epileptic, who, for a day or two previous to his nocturnal attacks, displays a remarkable intellectual brightness, with recollection of events that happened long before; but the sparks of lucidity go out with the onset of the attack. During this time he becomes very irritable, mischievous, and subject to violent impulses. This epileptic, who has been such since infancy, presents a well marked microcephalic type, is besides a monorchid, and could not afford a more striking illustration of physical and mental degeneracy, since several of his paternal and maternal ancestors are epileptics or paralytics.

In some instances it is not the accession of the fit which brings back to the mind its originating, painful or frightful cause, but the reverse takes place, the unexpected recollection of the emotion superinducing the attack. Van Swieten reports two such cases: one that of a child who became epileptic upon being frightened by a dog, and who would be afterwards thrown into a fit whenever he heard a dog bark. In the other in. stance, the fit recurred whenever the patient recalled to mind a frightful impression which caused the first attack. Maisonneuve saw a boy seized with paroxysms, whenever he remembered the dreadful stories about ghosts with which he had been scared in his infancy. A girl, under my care, was, while menstruating, completely overcome by fright at a fire in her bedroom, and suffered in consequence a great nervous 
disturbance with convulsions, which soon recurred with a distinctly epileptic character, and have been very often superinduced on hearing the bells ring a fire alarm.

The intellectual aura not only annoys and distresses the patient, but also raises the most terrible impressions, often irresistibly leading to impulsive actions which are indeed the chief source of the unaccountably sudden change in feelings and the automatic acts of violence preceding the attacks. Not infrequently the paroxysm does not break out in full force, and then it is represented by the intellectual aura, or the morbid impulse is devel. oped as its exponent. I have ascertained that delusions and hallucinations are ordinarily concealed by epileptics, and that they only describe them when pressed on the subject, or driven unawares to speak about them. The statistics I have kept of 267 cases of manifest epileptic insanity, show that morbid sensorial phenomena of various kinds have existed in 86 per cent. of the cases. Hallucinations of hearing are recorded in 62 per cent.; of sight in 53 per cent.; of hearing and sight in 42 per cent.; and of smell in 6 per cent. Finally, about 30 per cent. of the cases have displayed disturbance of general sensibility, (anæsthesia, hyperæsthesia, numbness, etc., etc.) If we take into consideration the frequency of these false sensations in epileptic insanity, it will not be difficult to realize the manner in which its victims are fascinated by the feelings they experience, and which ordinarily assume the most frightful or deceitful character. The eminent Brierre de Boismont, than whom no more competent authority could be presented on the subject of delusions and hallucinations, disapproves of the manner in which those who have discussed the legal responsibility'of epileptics, have completely thrown aside the relations between hallucination 
and epilepsy, in the epileptic shock which only affects the will. He reports several observations in support of the frequency of hallucinations with epilepsy, and says:

"Sometimes the fantastic figures address the epileptic in words, they insult him or command him to do something. It is probable that many crimes committed by these unfortunate beings, and for which some have been severely punished, were but the result of hallucinations of hearing and of sight." * * "These hallucinations are generally of an alarming and sinister nature."

"A countryman told us that in an access which preceded his admission to my house, whilst working in the field he seized a scythe and commenced cutting everything before him, incited by a voice which bid him to do so. After having traversed a great extent of arable land, he stopped, worn out by fatigue, near a well, and there fell asleep. If he had happened to meet with any living creatures, what misfortunes might there not have been to deplore? Esquirol, who had remarked the extreme terror caused to epileptics by their hallucinations, asked if it might not be this feeling which impressed on their physiognomy the character of fright or indignation which belongs to these patients during the access. Hallucination and illusion ought to be taken into consideration with reference to the instinctive and sudden acts of epileptics."*

One of my patients in his nocturnal attacks, sees a man in the corner of his room, and begins to cry in great terror and distress. Another hears a voice abusing him, and assaults the bystanders. Another can tell for an hour or two before going into a fit, by a pe. culiar lameness and dreadful pain in the legs, extending to the groin, and hearing at the same time the ringing of distant bells, which recedes as the fit approaches; at these times his feelings become very distressing, and he remains in a bewildered state. Another patient, again, while the attack is pending, feels distressed by a most offensive smell, with great fear, and a propensity to bite those near him. A woman, hears for three or four

* Hallucinations in their relation to Medical Jurisprudence. Medical Critic and Prychological Journal :' Vol. II, 1862 ; p. 78. 
hours before her fits, a constant piercing cry, like that of a child, which harasses her to such an extent, that she can not be approached without answering in a violent manner. The epileptic who killed Dr. Geoffrey, of the Avignon Asylum, heard, several days before the murder, a voice which said to him, "Kill the doctor, if you don't, you'll be unlucky."

One of the epileptics among the cases reported by Dr. John P. Gray, in his valuable memoir "On Homicide in Insanity;" "anticipated his seizures, and requested to be placed in his room and to have no one approach him suddenly. He experienced at this time pain in the head, a sensation of ringing in his ears, dim. ness of vision, with a vague idea of impending danger. His violence was ocçasioned by the delusion that persons were attacking him with the intention of killing him ; and on several occasions, while alone in his room, he had a distinct sensation of a blow upon the head, when he would immediately begin a furious contest with imaginary enemies."*

I am not, however, prepared to go to the length of looking upon all the psychical phenomena and impulsive actions manifested by epilepsy, as evincing a mental aura, or a false sensorial perception; because they may proceed also from the shock, that mainly affects the will, superinduced by the disease; and, the shades and modifications of which, true insanity have not as yet precisely established. Nor does the existence of a mental aura favor or aggravate the predisposition to epileptic insanity. Boileau de Castelnau has said, that epilepsy deprives its victim of estimating the reach, or appreciating the motive, or controlling the exaggeration of its animosity. Delasiauve no less forcibly asserts, that epileptic susceptibility not only helps evil instincts, but may by itself give rise to them, and hy 
raising and inspiring the idea of a misdeed, may drive fatally to its accomplishment. I have on many sad occasions seen the statements of the eminent authorities just cited corroborated. I an satisfied that the passions and appetites of the epileptic may be roused through his morbid susceptibility to an unaccountable degree, either before or after, or contemporaneously with the attack. But the phenomenon may be effected by the same natural agencies that would ordinarily operate on a healthy mind, while no attack is brood. ing; and the feelings in this wise excited, may act in their turn like any violent emotion, and originate an epileptic fit. Such an extreme irritability and violence to react, with its accompanying inpulsive actions, con stitute a train of phenomena which are only observable within the sphere of action of the epileptic malady in its progress. I have never noticed them when the epileptic appeared in a state of convalescence or recovery, nor when the attacks were of rare occurrence, without any effect on the mind. That this shock to the will, or unnatural reflex excitability of the nervous system attending epilepsy; may determine efficiently the extreme exaggeration of passions and emotions, which culminate in an epileptic paroxysm, is a fact apparent from several cases of my own and other alienists, although they were not reported by them to illustrate this point.

Case IX. A girl, aged 18, suddenly turns very pale, with eyes wide open, staring in front of her; she drops the head repeating several times, "mother, mother," and recovers consciousness in one or two seconds. She is troubled besides, with convulsive fits, and when the petit mal occurs frequently in a day, it rend. ers her very destructive, and also foul in her language. She has assaulted and threatened to kill her mother during such periods. This girl felt a resentment against 
one of her aunts, who objected to her going to places of amusement. On this account she could not bear her presence without giving vent to her animosity in the most bitter reproaches and insults, until a convulsive fit broke out. The fact recurred so regularly under these circumstances, when no indication of a fit existed, and the efforts of the family to remove the unjust feeling, proved so powerless, that it was necessary to prevent the interviews between the aunt and niece.

Case X. A Catholic gentleman, aged 36, epileptic since childhood, and having two paternal uncles insane, suffers from grand mal, attended with religious monomania for a few days after. He manifests in these attacks a great desire to go to church, where he remains several hours in devout prayer. These desires, for obvious reasons, were in the beginning opposed by his family, and this greatly heightened his excitement and anger, inducing every time an epileptic paroxysm. To try the experiment, he was once allowed to go to church accompanied by his servant, and no ill effects or fit ensued. It is needless to allude to the miraculous influence attributed to prayers and pious devotion, in averting fits which were the outgrowth of excessive anger and mortification.

Case XI. A boy, eight years old, has been, since infancy affected with left hemiplegia, and frequent instantaneous attacks of jerking which throw out the limbs, in addition to fits of grand mal. Paralysis is regarded as a hereditary disease in the mother's family. This boy exhibits a most irritable and angry disposition, and when his wishes are not promptly gratified, or he is corrected by his parents, he falls into a rage which is soon succeeded by an epileptic fit. Treatment has greatly improved his mental condition without completely arresting the epileptic paroxysm. 
Case XII. Two years ago, I was consulted in the the case of a boy sixteen years old, who had nocturnal epilepsy, induced, as his father believed, by masturba tion, though no proof existed to that effect. A physician had asserted that masturbation was always the cause of this kind of epilepsy, and on this assurance the father endeavored to obtain a confession from the boy, who denied the accusation, though he acknowledged that he had heard other boys at school speak about such a bad habit. This examination, made one Sunday morn. ing, wounded the boy's feelings so deeply that he did not breakfast, but remaining in his room taciturn and sullen, had the first diurnal paroxysm. This sad result carried to the father's mind the conviction that he had detected the real cause of the disease. From that day, whenever the boy has been questioned on this point, by his father or any physician, as I have had occasion to witness, his resentment becomes so extreme, that he refuses talking any more, and falls soon after in an epileptic fit. He has entreated his father not to mortify him by investigations of this character, and has even threatened to commit suicide if his wishes were not complied with. No other cause has ever induced, in this case, a diurnal attack.

The following interesting example is mentioned by Boileau de Castelnau :*

CASE XIII. "Dr. Valériand was, in March, 1830, directed by the Attorney-General of Paris to examine C___indicted for having inflicted wounds on another man which proved fatal; the existence of epilepsy was verified, and, in addition, that $\mathrm{C}-$ would be thrown into epileptic convulsions by the least contrariety and that the slightest moral emotion would induce them. Dr. Valériand, consequently, declared that

* De l' epilepsie dans ses rapports avec l' alienation mentale, Paris, 1852 : p. 34. 
Journal of Insanity. [April,

C - could not be tried, as he was in a state bordering on dementia, in which he will probably end. The Doctor further advised that $\mathrm{C}-$ should be transferred to the division of epileptics in Bicêtre."

Two more remarkable instances are cited by Devergie, who obtained the details of them from Moreau de Tours, under whose charge the patients were.*

Case XIV. "In 1841, Moreau de Tours, had under his care at Bicêtre, a young man from twenty-five to twenty-six, who had been condemned to death for murder, but whose sentence had been commuted to twenty years' imprisonment. He was epileptic from infancy, and had received an accomplished education. He came to Paris with a young woman whom he expected to marry, and whom he loved extremely; but becoming jealous of her harmless flirtations, quarrels arose. One evening, after a long promenade $\mathrm{X}$ - who for two days had been feeling unwell and giddy, came into the hotel and found his mistress sound asleep. Suddenly he thought how unfortunate he would be if this young girl should prove false to him, and taking a pistol killed her. He immediately fell in an epileptic paroxysm and was found struggling in convulsions by the persons who hastened to the room."

CASE XV. "A young man, aged 22, had suffered for five years from attacks called, by the physicians, epileptic fits. 'I am unwell,' said he to Moreau de Tours, ' every five or six weeks, having sometimes several attacks in one day. I had never noticed that this malady impaired my health until I was seized a month ago with fears of becoming insane on the following account. I had a trifling disagreement with one of my friends, and two days after, having awoke all confused, the idea of this quarrel returned to my mind, and its recollection

* Bulletin de l' Académie de Médecinc, Vol. XXVI, 1861 : p. 436. 
excited me to such an extreme, that I conceived a feeling of hatred and revenge. Thereupon, I rushed for a dagger, put it in my pocket and hastened to my friend's lodg. ings, with the intention of murdering him. Fortunately, I had scarcely pulled the door bell, when I dropped down in one of the fiercest paroxysms I ever had, my very friend being the first to come to my assistance.'"

Devergie concludes from these two interesting cases, that it is never during the seizure, but in the interparoxysmal interrals, that criminal ideas are conceived by epileptics, and always in cases of confirmed epilepsy. Most assuredly, it is in confirmed epilepsy that these psychical phenomena generally spring up; but the forcible illustrations chosen by Devergie, obviously demon. strate that the mental disorder, the irresistible impulse, may also immediately precede the epileptic seizure, form. ing a part of it. These examples exhibit the excessive irritability that foretells the paroxysm. In either case, however, the single isolated occurrence of the phenomenon, its origin and nature, precludes the idea of regarding it as an intellectual aura in the sense properly applied to this term.

My own cases, nevertheless, leave no room for doubt as to the manner in which a feeling or passion, which has received no previous uncurbed indulgence, and like that which may be suddenly aroused in a sound mind, may be heightened, by the unhealthy susceptibility of epileptics, to such a degree as to culminate in the onset of a paroxysm not otherwise induced. Those in immediate charge of epileptics have an almost daily opportunity of verifying this fact; and the records of psy. chological medicine afford a great many more proofs of the state of mind under consideration than those $I$ have already mentioned. I referred, when considering the criminal responsibility of epileptics, as illustrated by Vor. XXIX.-No. IV.-F 
the case of David Montgomery, to the example detailed by Boileau de Castelnau of a convict, in the prison of Nismes, who had an epileptic fit after quarreling with a companion, whom he afterwards stabbed and came near killing, for having made jest of his attack. It does not seem to me improbable, in the case of Montgomery, that jealousy might have exerted not only the most evil influences in his mind that he would fain avoid, but also the most energetic to induce the epileptic fit, which seemed to have occurred about the moment of the crime, as betrayed by the partially dressed and bewildered condition in which Montgomery, with a razor in his hand, ran out of his house to the neighboring barn, after slaying his wife. I can not avoid recalling one last example of this state of mind, cited by Dejæghire, in which are also fitly set forth many typical signs of epileptic insanity, while remaining as an eloquent record of the punishment of a madman, not only unjust but harmful.

CASE XVI. Rœgiers, aged 30, of stroing constitution, is the son of healthy parents. When seven years old, he was seized, upon a sudden fright, with an epileptic attack, which was soon followed by a second and third until the fits recurred with a very fearful frequency, increasing every time in intensity and duration and lastly degenerating into a true rage. Everybody dreaded him, and woe to him who should oppose the execution of his will, when he was laboring under the forerunning uneasiness of an attack. Once this epileptic fury passed, the patient loses the memory of whatever has occurred, and regains his normal state of a calm and peaceful though extremely irritable man.

The fits of Rœgiers recur particularly during the night, announced by the following signs: his face becomes animated and of a purple red; his eyes brighten 
and seem to come out of their sockets; his sight is soon rendered dim and all appears in confusion around him; the head feels very heavy and aches, the veins of the neck grow large, and until the moment in which the fit reaches its height and throws him into a complete insensibility, he struggles furiously, and if unrestrained, gives himself up to every kind of dangerous act.

Rœgiers had a fight with a man named $\mathrm{B}-$. Judged upon the point in controversy by the Court of Courtrai, he was condemned to a few months' imprisonment. Ragiers protested his innocence as to the charge brought against him. Furthermore, on leaving the Court, he shook hands with $\mathrm{B}-$, assuring him that he entertained no grudge against him, since he could not be held accountable for the wrong decision of the Court. However, it is this very man B- whom he after intends to kill, and to this effect Rœgiers was seen on the day of the murder, steadily sharpening his knife for several hours on a grind-stone, and repeating incessantly, "I shall know how to have you." $\mathrm{He}$ then goes out in broad daylight, holding his knife, runs to B-, who lives in a very populous ward, and enters his house with assurance. But B-, on seeing Rœgiers coming with a knife, escapes through a back door. Rœgiers chases him, stabs B-.'s sister, who endeav. ored to defend him, and finally overtakes him and rushes upon his victim like a tiger. He inflicts upon him a deep wound in the neck and plunges his nails in it to enlarge it. A great crowd hastened to the spot, but the most daring were afraid of going to the rescue of the unfortunate $\mathrm{B}-$. It was not until Rœgiers fell down that they took hold of him, and bound him with cords to a wheel-barrow. To every question put to him by the Court of Assizes, and in reply to any details concerning his horrible crime, Rœgiers gives always 
the same answer: "Since you make me aware of it, sir, I must needs believe it, but I completely ignore it."

"The first physlcian examined on the mental state of Rœgiers, declared that he enjoyed full possession of his reason. Rœgiers was condemned to death, but the sentence was commuted to penal servitude for life and the exposing for one hour. While suffering this last punishment, he was seized with such violent convulsions, that the executioner was obliged to place him in a chair, where he had the greatest difficulty to secure him."*

The proofs of the propensities and wild instincts that may arise out of the state of epilepsy arc, therefore, too precise to be any longer disregarded ; whereas the cases here noticed and many similar ones that might be added to their number, confirm how insufficient, motive, premeditation, and design are, to supply trustworthy evidence on which to rest the recognition of culpability in relation to the insane. Enough facts have been set forth to make manifest, that, whatever might be the apparent guilt coloring their actions, epileptics are irresponsible agents when laboring under the perverted mental condition we have been considering. This state of epileptic insanity, which so deeply and greatly affects the volitional acts, can not be measured by common sense, which, as Maudsley says with great propriety, in a matter of science, represents com. mon prejudice or ignorance, and can not be applicable, as a standard of measurement to that, the essence of which is, that it is not common sense, but insanity. I have no wish to disparage judicial opinions and discussions, but I can not refrain from agreeing with the English alienist just named when he says:

"That the law representatives have deemed it sufficient for all possible cases, and have thought themselves excellently well employed while they were putting new wine into old bottles; they

*Annales Médicales Belgcs, 1843, quoted in La Folie derant les tribunaux, par Lcgrond du Saulle: Paris, 1864; pp. 422-424. 
would search in a statute of Elizabeth for regulations applicable to a steam engine or a balloon, and would insist that science can not reveal anything which the law has not contemplated. When we see the Judge, whose wisdom, age and office might well attest, thus irritably engaged in laboring to make the old garment cover the new fact, the reflection can not but occur, that it is well for truth that man is mortal."*

In one of the previous cases, attacks of sudden jerking of the limbs have been noticed, and I will briefly point out the importance and relation of these accidents almost ignored by every author excepting Moreau de Tours, $\uparrow$ who has called special attention to it. This jerking (secousses,) or sudden instantaneous tetanic contraction of the limbs or body, may occur as the immediate precursor, or as an intermediate accident, or less frequently again, as the substitute of the attacks. Moreau de Tours asserts that he has met with only one instance of the last nature, in a woman at the Salpetriēre, who remained for ten years free from fits, which were replaced by light jerkings of the arm, recurring sometimes so rapidly that she could not count them. In addition to the case here cited, I have observed the jerkings in a boy who has continued four years without fits, but subject to jerkings of the arms, as though they were acted upon by an electric discharge. The phenomenon, exclusively located again in the arms, existed for three years before the fits supervened, in a patient who became epileptic from traumatic injury to the skull, and whom I trephined fourteen years after the infliction of the injury, with complete recovery from the fits. The jerks are repeated several times before the attacks of grand mal, in the case of a young man I have been re. cently attending with my friend Dr. John P. Gray, and who in one of his attacks of mania attempted to kill his

* Homicidal Insanity, Journal of Mental Science: Vol. VIII, 1863; p. 332.

†Union Médicale: 17 Juin., 1853; p. 553. 
mother, firing at her with a revolver. Another, a woman with grand mal, became free from it when the catemenia disappeared, and has remained since subject to sudden jerkings of her whole body, occasionally repeated as many as eight or ten times in one hour, causing dizziness and rendering her very fretful, with an unnatural laughter, and very stubborn. Moreau de Tours regards this accident as evidence either of a latent or of a manifest state of epilepsy; and my observation, so far, bears out the assertion, as also that the phenomenon belongs exclusively to epilepsy; for I have never met with it in any other disease. This acident should not be confounded with the local convulsions of some of the limbs that may herald the fit, as a tiue motor aura, and which have been described by II rpin and other authors. It is chiefly on account of its association with the latent forms of the disease, and the consequent medico-legal aid that its presence may afford for the detection of obscure epilepsy, that my remarks have been prolix on this accident, which I believe distinctly marked in this case of homicidal epileptic insanity, reported by Maudsley, and where it supplanted the epileptic fits.

"A peasant aged twenty-seven, had suffered from his eighth year with epilepsy; but two years ago the character of his disease changed, and instead of epileptic attacks he was seized with an irresistible impulse to commit murder. He felt the approach of his attacks sometimes beforehand, and then begged to be bound in order to prevent a crime. 'When it seizes me, I must kill some one, were it only a child.' Before the attacks he complains of great weariness; he can not sleep, feels depressed, and has slight convulsive movements in his limbs."*

I now come to a matter in which medical science and law are in broad dis-accord, as it subverts the main test of any form of insanity which the law acknowledges; it is the capacity to distinguish good from evil, or right

\footnotetext{
* Loco cit., p. 334.
} 
from wrong. The state of unconsciousness not immediately connected with visible epileptic fits, the gap during which subjective impressions, consciousness to realize the feelings, and the control of volition are withdrawn from the epileptic, who, like a dreaming man sees, but does not appreciate his outward relations, is one of the most characteristic traits of cerebral epilepsy. Dr. Ray in his classical work on Medical Jurisprudence, after commenting in the most able manner on the interesting points relating to the cases of Fyler, Bethel and Win. nemore, remarks that the state of unconsciousness in which these epileptics committed homicide is supported only by their own statements, and under the circum. stances should not be implicitly received. "No such condition," says our eminent author, "had been previously observed in Fyler or Bethel, but Winnemore stated that he once rowed about in a boat in the river several hours without being conscious of the facts, hav. ing been told of it by those who saw him. The same objection lies against this story. No writer on epilepsy speaks of any such feature of the disease as the kind of unconsciousness alleged to have occurred in these cases." * This is the only distinct allusion I have found in reference to the state of unconsciousness I am about to examine. Notwithstanding his cautious reserve in the passage just quoted, Dr. Ray believes, as he afterwards says, that, "such loss of consciousness is not so very far removed from the psychological impairment ordinarily attributed to epilepsy as to render its occurrence highly improbable."

It may be proper, to form a correct notion on the sub. ject, that before going any further I should establish the two distinct conditions under which this state of unconsciousness may be observed in relation to epilepsy.

1. In contemporaneous occurrence with a real fit, more

* Medical Jurisprudence of Insanity. Fifth edition, 1871 : p. 486. 
ordinarily of the form petit mal, either before, or, more frequently, after it: 2. As a condition entirely independent of any visible fit, unless it be giddiness or slight vertigo, then assuming a characteristic phase of cerebral or masked epilepsy, and constituting a true transitory but not instantaneous insanity. The impulsive acts of epilepsy are instantaneous; yet the state of insanity in which they are almost always produced has a transitory duration, varying from hours to several days, in which sense I use the term transitory insanity. I pass to a condensed report of such of these cases of legal interest, and commence by reproducing one, highly typical, and belonging to the first category.

Case XVII. A young man fell from the top of a ladder fifteen feet high, and became epileptic thereafter. He would, while in conversation, stop suddenly, drop his head and look as if dead, but would regain consciousness in a few seconds, entirely unaware of his condition. One evening, after one of these attacks, he went into the street, took a horse and buggy which he found in front of a house, rode over a mile and a half to his father's grave, pulled the flowers from the bushes planted over it, and brought them home to his mother, whom he invited to take a ride. Being asked where he procured the horse and buggy, he replied that he found them lost in the street. His mother directed him to go forthwith to a livery stable and there leave the horse and wagon that they might be returnel to their owner. He started to do so, but left the horse and buggy for keeping at a livery stable, as his own. When discovered by the owner, the transaction was looked upon as a lar. ceny, thereby causing great mortification and annoyance to his family. The boy, however, could never account for his conduct, and completely forgot every circumstance connected with it. On another, more recent occasion, 
he left home after the attack, and while wandering through New York, he came across a sailor's agent, who engaged him to go as a sailor on board an English vessel starting for London. The agreement was signed, and after leaving almost all his pay and some of his personal effects, he embarked for England. The captain discovered from the start that he was no sailor, and finding him very flighty, exempted him from going to the top of the masts, and assigned to him very light duties. A few days after his departure, on coming out from his state of epileptic insanity, he expressed great surprise at finding himself on board a vessel bound for London, and completely ignorant how he came to be on board. The mother discovered through the police the departure of her son, and took the necessary steps to have him brought back. He has similar attacks of insanity after nocturnal paroxysms, or fits of petit mal as described above, but is very rational and gentle in the intervening periods between the paroxysms, which render him very mischievous, inclined to be constantly running or wandering about, and prone to acts of violence.

Case XVIII. A young lady, aged 28, has suffered from severe grand mal and petit mal, from the age of dentition. Her mother and brother are insane. For the last five years the grand mal has occurred only at night, about the menstrual period, and at the same time the fits of petit mal have increased in severity. The intellectual faculties of this woman, impaired at this time, display at others no change beyond the peculiarities and impulsive traits of character, obvious only to those who watch her closely. After the attacks of petit mal, she remains in a most curious state, and talks and argues with an acuteness and loquacity not before natural to her; she re- 
lates with great correctness passages from the Bible, or writes the most strange and incoherent letters. While in this condition she is constantly acting as though she were listening to something, and frequently stops in the conversation to assume such attitudes; she also becomes very destructive, often strikes at those who touch her, and does not seem to recognize or remember the names of persons familiar to her, though replying pointedly, and coherently to any of their remarks. This state persists for one or two days before the nocturnal attack after which she feels depressed, with no recollection whatever of what she has done before.

Let me now refer to cases of the second category, which are the most perplexing and those on which I chiefly desire to insist.

CASE XIX. I have had this patient under my care since 1867 , and observed him very closely, assisted in the beginning by my learned friend Dr. L. B. Edwards, of Richmond, Va. He is 35 years old, epileptic since puberty, and was at first subject to furious mania lasting about three weeks after the fits of grand mal. His condition improved under treatment, and gradually the attacks changed into vertigo, often repeated, accompan. ied with religious monomania and refusal to speak with any body. After an absence of several months in Nova Scotia, he returned to New York, two years ago, consid. ering himself cured, though acting very queerly at periodical times. No fits had occurred for sixteen months, a longer freedom than had ever been observed before. At this time, he would lose every three weeks the mem. ory of the most trivial circumstances, frequently inquiring for noises that he heard, or obstinately insisting upon going out to wander at a venture for hours, or to visit persons with whom he was not acquainted. On other occasions he would enter a shop and buy articles he did 
not want; he was once arrested for assaulting a clerk in a dry goods store, who refused to let him carry away some goods he had selected, unless they were paid for. He has in like manner caused considerable annoyance to his brothers in ordering things and denying on their reception that he had bought them. He acts, throughout these paroxysms in an apparently rational way, answers coherently, but at once forgets what he has said, and repeats twice the same word or question addressed to him. He further displays a slight but evident quivering of the hand and of the facial muscles. This state is followed by several hours of profound sleep, from which he wakes in complete oblivion of what he has done.

CASE XX. A young man, aged 19, with a paternal cousin epileptic, has suffered for six years from grand mal, after being sunstruck. For the last year the fits occurred as a sort of vertigo, without other convulsions beyond a slight quivering of the facial muscles, which came on generally in the morning; subsequently, instead of vertigo, he exhibited occasionally for hours, or a whole day, an utter unconsciousness of what he did. His mental power in the mean tine was failing and his memory had become very much enfeebled. The first instance of his unconscious state that attracted particu. lar attention, was the following: He left his father's office, where he was employed, to call on a merchant with whom his father traded extensively, and told him that it was of no use to look after the payment of some pending account, and asked in addition, for the closing prices of certain merchandise that he could take them to his father before four o'clock that day. It is need. less to remark the great surprise that this conduct caused his father, who looked upon it as an indication of sudden insanity. On another occasion, he started 
early in the morning for Mott Haven, where he stopped at his uncle's, who, struck at the strangeness of his acts and manner, brought him back to his father. He was then planning all sorts of mercantile projects. The day after these attacks, he was quite himself, but could not account for, or remember anything of what had occurred to him.

Case XXI. A gentleman, aged 42, had attacks of grand mal from the age of 12 until he was 22 , but no fits have occurred since. He, however, has been subject for the last five years, to dizziness and headache, and must also have had some nocturnal attacks, from the statement of a brother, who has heard him breathing very heavily sometimes in the middle of the night. It was impossible to arouse him at once from such a condition. He is very passionate, and has had, at variable intervals, attacks, during which for one or two days he believes himself another man, living in London, where he resided years ago, and acts in the most extravagant manner in regard to his affairs, and is very licentious. He becomes drowsy at the end of these attacks, and after sleeping for twelve or fourteen hours, awakes in a state of confusion, utterly unconscious of his previous actions and conduct.

Case XXII. A young man, about 20 years of age, brought from the Tombs to the City Asylum, was not able to furnish any account of himself until several hours after his admission. I then ascertained that he lived with his mother, in Hartford, and was subject to epileptic fits, that always had occurred during the night. $\mathrm{He}$ could not explain why he started from Hartford, nor what he did before taking the night steamer where he had a fit early in the morning. He arrived at New York quite incolherent and stupid, and was taken in charge by the police. $\Lambda$ t the asylum this 
patient had several attacks of cerebral epilepsy, when he would become very impulsive and dangerous. One morning, after getting up, he assaulted another patient who addressed some remarks to him, and wounded him about the face, with a vase he threw at him. During the fits of cerebral epilepsy, which lasted two or three days, he acted entirely automatically, without preserv. ing afterward the least recollection of what he had done throughout this stage.

These are not the only evidences I could bring forward of this peculiar form or state of unconsciousness which may be displayed by cerebral epilepsy. A signal illustration of it is furnished by the case of Winnemore, as presented by Dr. Ray, and it is no less glaring in the example produced by Dr. John P. Gray, during the trial of Montgomery, and noticed in one of the preced. ing pages of the Journal. The same condition is strikingly portrayed by Dr. Laurent in his interesting report of the epileptic who murdered Dr. Geoffrey, of Avignon, and may be equally recognized in many of those instances, received with so much wonder and incredulity, of instinctive or impulsive insanity, actually springing out of a mistaken or undetected epileptic affection. In view of these facts, how are we to decide on the legal responsibility of a man criminal by reason of his disease, who acts and talks apparently rationally throughout a state of epileptic or cerebral insanity? Before answering the question, let me bestow particular notice upon a recent exposition of the law, which could not be more pertinent to the point, as laid down by the learned Judge Mullin, of the Supreme Court, in the decision denying reversal of judgment in the case of David Montgomery.

While I am of opinion, said the presiding justice, that, for some days before the killing, the prisoner was partially insane, and at 
some times during that time more so than at others, there is no evidence that he was not capable of distinguishing right from wrong at the time between noon on Saturday and the commission of the crime. Indeed, we might go further, and say that at no time except vhen he was in one of the epileptic fits, is it proved that he was incapable of distinguishing right from wrong. Drs. Gray and Cook give it as their opinion, that the disordered state of mind produced by one of those fits may continue for days, and the person having it be unconscious of what is passing, notwithstanding he may act and talk rationally during the time. If Courts are to act upon this as an established fact, I do not see but that all attempts to punish such persons must be given up. If a man may be utterly insane and yet act and talk rationally, it is impossible by any test to determine where responsibility for crime attaches. We may convict a person altogether incapable of committing crime. I do not make these remarks because I doubt the correctness of the opinion of these learned and intelligent gentlemen, but I say, that while the greatest degree of care and caution must be exercised in determining the question of capacity to commit crime, yet we must hold the man responsible whose acts and declarations prove him to be so far sane as to know that an act that he commits is, by the laws of God and man, wrong. If, under the rule, a person that is irresponsible is punished, it must be submitted to, or entire immunity must be given to persons proving insanity. I am of the opinion that the conviction was right, and should be affirmed. Judgment affirmed."

It would be hardly relevant to my purpose to enter into the obvious inconsistency and uncertainty of this authoritative statement, which acknowledges the exist. ence of insanity, and admits in the next breath the non-recognition of its manifestations. I will, therefore, confine myself to the reply to the query I have already put, and repeated essentially in Judge Mullin's decision; to wit, is it really impossible by any test to determine the crim. inal responsibility of such insane epileptics?

It is a recognized principle of psychological medicine, that hallucinations and delusions are not the only ex. ponents of insanity ; that, in his intervals of calm and quietness, when not raving, the lunatic may act and talk

*Abbott's Practice Reports; New Series, Vol. XIII., p. 252. 
rationally; and, that the cerebral activity is at these moments accomplished by the acquired habit or process of thought, without the mind having a real recognition of its operation,-wherefore these acts are ordinarily not appreciated or remembered. We frequently meet with recovered lunatics who do not retain the least recollection of entreaties and requests they earnestly made, nor of their conversations, in moments, which seemed periods of perfect rationality, through the progress of their past insanity. Curiously enough, they on the contrary are often capable of furnishing a circumstantial account of their feelings and surroundings during the exacerbations of their madness. It further requires no proof, that we rely on the purely mechanical operations of the mind, and on the ordinary agencies that bring them into action, to maintain the discipline and order of our lunatic asylums, without need of punishment, chiefly by endeavoring to restrain the disordered intellect and unbridled impulsive instincts of the insane by a judicious counteracting opposition, wisely rendered unfelt in its enforcement. Then, again, if the instrument should become so materially impaired that the mind's faculty of preference and estimation be suspended, are we to conclude therefore, that lunatics should be held respon. sible for what they have no power to do, even though appearing to our sane minds as capable of distinguishing right and wrong, as of sacrificing their lives, or that of their fellow beings, to the overwhelming feelings and uncontrollable actions under insanity? Certainly it would not be logical to measure the nature of such morbid actions by the standard of sound feelings. In regard to the unconsciousness of epileptics while thus rationally acting in their paroxysms of cerebral epilepsy, it is far from being an exceptional or unique phenomenon of the kind. Is not the mind in active ope. 
ration during somnambulism and consciousness completely obliterated, though the individual nevertheless displays capacity to distinguish right and wrong? And yet, the law entertains no prejudice to exempt from pun. ishment any criminal act perpetrated during somnambulism. In this place, however, I do not attempt to discuss the legitimacy of punishment, to which I take no objection, but simply to ask-why should cerebral epilepsy, which so much resembles somnambulism in its manifestations, be visited with the punishment which the law does not award to the latter?

There are, however, more cogent facts to convince us that the state of cerebral epilepsy, referred to by Drs. Gray and Cook, displays characteristics of its own, which will enable a physician experienced in the phenomena of epilepsy to disclose its existence. In this more than in any other case where the detection of insanity is attempted, the antecedents, as Dumesnil has established it with great propriety, are elements of the utmost importance. The hereditary predisposition, as we may see by the examples here reported, stands prominent in this regard. Truthfully has Maudsley asserted, that, " the hereditary madman often gives the idea of a double being; appeal to his consciousness and he seems rational and nowise deranged, but leave him to his own devices and his unconscious life appears to get the mastery and to impel him to extravagant or violent acts." The periodicity of the attacks is a phenomenon I look upon as constant in cerebral epilepsy. I have met with no case in which I have failed to trace precisely their previous occurrence after close investigation, or to verify their repetition while the patient was under my immediate care. The mental phenomena of masked or cerebral epilepsy recur with the periodicity peculiar to the other epileptic paroxysms. They are 
not solitary. They supervene after a more or less prolonged stage of incubation, and, though acknowledging the same source and nature as the other attacks which they substitute, they exhibit, however, a much longer duration, seldom lasting less than a day, and often persisting for two or three. These paroxysms, as already asserted, may equally alternate with those of petit mal or grand mal, just as these latter may exist combined. Cerebral epilepsy, nevertheless, ordinarily constitutes by itself the epileptic malady, of which it implies an advanced stage. Its supervention is evinced by other signs besides extreme susceptibility and impulsive actions, and it is not rare to find it associated with religious monomania and erotomania. The volubility and instantaneous changes usually attending this state may be sometimes replaced by an opposite condition of complete immobility and silence, the epileptic remain. ing for hours motionless, with a sullen expression of countenance, and even involuntarily passing his urine or excrements, like those with stupidity or melancholia attonita. I have observed this condition to the extreme of verging almost in catalepsy. Giddiness becomes also a symptom of this state, with more or less profuse perspiration of the head. In three instances epistaxis has supervened during or immediately after the attack, and in clear connection with it. In the majority of cases I have personally observed the existence of hallucinations and delusions of a distressing character which prompted the patients to acts of violence. Hallucinations of hearing have been the most frequently detected; they further appear particularly noticeable in the cases here quoted from Laurent and Gray, as also in many of those recorded by Brierre de Boismont and other authors.

VoL. XXIX.-No. IV.-G 
The physiognomy of a patient with cerebral epilepsy bears in a high degree the heavy lost look and unmis. takable stamp with which epilepsy brands its victims. The bloated and livid appearance, with the slight quivering of the face, the tremor of the limbs, and the moral perversion that springs out of the malady and leads to shameless vicious habits, or intemperance, account for the frequent arrest, and punishment like drunkards of individuals suffering at the time from cerebral epilepsy. The quick recovery from their fit of unconsciousness, strongly countenances such mistake. I have on many occasions, had under my care, patients sup posed to be laboring with delirium tremens, or alco. holic insanity, who after attentive inquiry proved to be inveterate epileptics, arrested in a state of cerebral epilepsy.

Another phenomenon, observed pretty regularly during the paroxysms of masked epilepsy, is a propensity of the patient to repeat one same phrase, and especially the words addressed to him. This echo sign, regarded by Romberg as symptomatic of cerebral softening, appears to me in these instances mainly indicative of a perverted will. I have noticed it with a remarkable constancy, and we see. it distinctly recorded in the case of Rœgiers previously cited.

The inception of cerebral epilepsy, when its signs are not well marked, may pass unrecognized by an unexperienced observer; but the transition from the paroxysm to a natural state of mind, so far as my observation goes, is always effected after a period of sleep, that seems required by the brain to recuperate from the shock caused by the malady. This is a point on which I have before insisted when examining into Montgomery's case, and to which may attach a great medicolegal value. This sleep may be prolonged several 
hours: I have observed it often accompanied by heavy breathing, or snoring, which makes it easily mistaken for the sleep of drunkenness. The case from Brierre de Boismont, and that of Bisgrove in 1869, who after dashing out the brains of his victim, laid down and went to sleep by him, are striking illustrations of the fact now pointed out, in addition to other instances that might be presented from the reports of other authors.

The state of unconsciousness I have tried to describe belongs properly to that form of intellectual petit mal so faithfully delineated by Falret. Indeed, it is act. ually one of its important phases, left unnoticed by the eminent French alienist, and by referring to the well known description given by Falret, the correctness of this statement may be verified. Nor should the deceit. ful form of cerebral epilepsy, which I have thus deemed worthy of separate consideration, be confounded with the entire transformation of character, that may result after one single fit, as in the case mentioned by Mauds. ley, or the special moral and intellectual dispositions which characterize epilepsy. These latter we know to be justly declared by Baillarger, as marks which, with. out constituting a state of insanity, nevertheless place epileptics beyond the common rule, and if not sufficient to render them unaccountable for all actions, extenuate at least their legal responsibility.

A few more words in conclusion. It is by an attentive study and unbiased appreciation of facts that we arrive at the elucidation of truth, and to no other end are the foregoing cases submitted. I have intention. ally avoided entering upon any speculation as to their significance, of which the reader may himself judge. The deepest feelings of humanity and compassion towards epileptics, whose dreadful malady has most 
especially attracted my attention for many years, observing them at all hours, and subjecting their cases to a strict analysis, move me to contribute this small portion of my results, feeble though it is, towards clearing away the obscurity that still covers the vital question of their legal responsibility. It will, however, be useless to talk and write about this or any other subject related to criminal insanity, if our energies are not directed to reform the procedure of our courts of law in criminal cases where the plea of insanity is interposed as a defence. Let a preliminary examination of the prisoner be intrusted to competent medical experts, fully to ascertain and accurately to estimate the question of insanity, before he be placed on trial ; and this system once sanctioned by our legislators and put into practice, the prevalent misconception of insanity, and its abuse in contravention of public safety, will be effectually checked, and no occasion left to accuse the law of inhumanity for sending either a homicidal epileptic, or any other reasoning madman to the gallows instead of to the Lunatic Asylum. 